Illinois State University

ISU ReD: Research and eData

Theses and Dissertations

$11-7-2016$

\title{
A comparison of the immediate effects of muscle energy technique and joint mobilizations on posterior shoulder tightness in youth throwing athletes
}

Maddox L. Reed

Illinois State University, mlreed7@ilstu.edu

Follow this and additional works at: https://ir.library.illinoisstate.edu/etd

Part of the Kinesiology Commons

\section{Recommended Citation}

Reed, Maddox L., "A comparison of the immediate effects of muscle energy technique and joint mobilizations on posterior shoulder tightness in youth throwing athletes" (2016). Theses and Dissertations. 702.

https://ir.library.illinoisstate.edu/etd/702

This Thesis is brought to you for free and open access by ISU ReD: Research and eData. It has been accepted for inclusion in Theses and Dissertations by an authorized administrator of ISU ReD: Research and eData. For more information, please contact ISUReD@ilstu.edu. 


\title{
A COMPARISON OF THE IMMEDIATE EFFECTS OF MUSCLE ENERGY TECHNIQUE AND JOINT MOBILIZATIONS ON \\ POSTERIOR SHOULDER TIGHTNESS IN \\ YOUTH THROWING ATHLETES
}

\author{
Maddox L. Reed
}

\section{Pages}

Background: Due to the extreme forces on the glenohumeral $(\mathrm{GH})$ joint during the throwing motion, and the high number of repetitions that occur during overhead sports, alterations in range of motion (ROM) are a common occurrence in overhead athletes, particularly baseball and softball players. The presence of limited GH motion that occurs as a result of posterior shoulder tightness can increase the risk of injury. Despite clinical evidence pointing to the use of joint mobilizations and muscle energy technique (MET) for the treatment of various pathologies, there currently are no data examining the overall effectiveness of joint mobilizations and MET to determine optimal treatment for posterior shoulder tightness.

Purpose: To compare the acute effectiveness of MET and joint mobilizations for reducing posterior shoulder tightness by increasing GH horizontal adduction and internal rotation ROM. 
Methods: Forty-two asymptomatic high school baseball and softball players were randomly assigned to one of three groups. Fourteen participants received one application of joint mobilizations, and fourteen participants received one cycle of MET, between pretest and posttest measures of passive GH internal rotation, external rotation, and horizontal adduction ROM. The remaining 14 participants served as the controls, and did not receive any treatment. Data were analyzed using separate one-way analyses of covariance, for internal rotation and horizontal adduction ROM at two time periods (immediately after treatment, 15 minutes after treatment application). The dependent variables consisted of the post-test ROM and the covariates were pre-test ROM.

Results: Acute results determined that the MET group had significantly more horizontal adduction ROM post-treatment compared to the control group ( $p=0.04)$. No differences existed between MET and joint mobilizations or joint mobilizations and the control group for horizontal adduction ( $p>0.16)$. No significant between group differences existed acutely for internal rotation ( $p>.28)$. There were no significant between group differences for either horizontal adduction or internal rotation at the 15minute posttests $(p>0.70)$.

Conclusion: The results of this study indicate that the application of MET to the horizontal abductors provides acute improvements to GH horizontal adduction ROM in high school baseball and softball players.

KEYWORDS: Baseball, Glenohumeral, Manual therapy, Range of motion, Softball 


\title{
A COMPARISON OF THE IMMEDIATE EFFECTS OF MUSCLE ENERGY TECHNIQUE AND JOINT MOBILIZATIONS ON \\ POSTERIOR SHOULDER TIGHTNESS IN \\ YOUTH THROWING ATHLETES
}

MADDOX L. REED

\begin{abstract}
A Thesis Submitted in Partial Fulfillment of the Requirements for the Degree of

MASTER OF SCIENCE
\end{abstract}

School of Kinesiology and Recreation

ILLINOIS STATE UNIVERSITY 
Copyright 2017 Maddox L. Reed 


\section{A COMPARISON OF THE IMMEDIATE EFFECTS OF MUSCLE ENERGY TECHNIQUE AND JOINT MOBILIZATIONS ON POSTERIOR SHOULDER TIGHTNESS IN YOUTH THROWING ATHLETES}

MADDOX L. REED

COMMITTEE MEMBERS:

Kevin G. Laudner, Co-Chair

Rebecca L. Begalle, Co-Chair 


\section{ACKNOWLEDGMENTS}

To the faculty and staff of the Athletic Training department at Illinois State University, thank you for your overwhelming support, going above and beyond the call of duty. Thank you for being adaptable and understanding amidst the tumult of change. The knowledge you have shared and the lessons you have taught have been instrumental in my development and growth as a clinician.

To the committee of this work, thank you for devoting your time to this body of research, the insightful feedback, and providing answers to my numerous questions. My success would not have been possible without your guidance.

Thank you to Jim Latal, ATC for your assistance in data collection.

To my family, thank you for the constant support, the endless love, and the encouragement on the days I struggled most. Thank you for keeping me grounded, lending ears and countless words of advice, and reminding me to remember the value of "Hakuna Matata".

To E.A.B., thank you for bearing the brunt of the bad days and being my motivation to bring this work to fruition. It would not have been possible without you by my side.

M. L. R. 


\section{CONTENTS}

\section{Page}

ACKNOWLEDGMENTS

CONTENTS

ii

TABLES

iv

FIGURES

V

CHAPTER

I. INTRODUCTION 1

II. REVIEW OF LITERATURE 3

Anatomy of the Shoulder 4

The Overhead Athlete $\quad 7$

Osseous Adaptations $\quad 12$

Soft Tissue Adaptations 14

Pathological Implications of PST 16

Treatments to Reduce PST 20

Conclusion $\quad 25$

III. METHODS 26

Materials and Methods $\quad 26$

$\begin{array}{ll}\text { Participants } & 26\end{array}$

Instrumentation $\quad 27$

$\begin{array}{ll}\text { Procedures } & 27\end{array}$

Participant Consent, Demographics, and Group Allocation 27

Data Collection $\quad 28$

Range of Motion Assessments 28

Interventions $\quad 30$

Statistical Methods 31 
IV. RESULTS

Results

Discussion

33

Limitations

37

Conclusion

37

Conflict of Interest

REFERENCES 


\section{TABLES}

Table $\quad$ Page

1. Participant Demographics 27

2. Pre-intervention Range of Motion Measures 32

3. Means and Standard Deviations for Horizontal Adduction Range of Motion $\left({ }^{\circ}\right)$

4. Means and Standard Deviations for Internal Rotation Range of Motion $\left(^{\circ}\right)$ 


\section{FIGURES}

Figure $\quad$ Page

1. Horizontal Adduction ROM Measure 29

2. Joint Mobilization Technique Position 30 


\section{CHAPTER I}

\section{INTRODUCTION}

Due to the extreme ranges of motion (ROM) and the high velocities placed on the shoulder, the glenohumeral joint is subject to tremendous amounts of force during the baseball throwing motion. Internal rotation velocity peaks at over $7,000 \%$ second, ${ }^{1}$ and torque forces at the peak moment of external rotation can exceed $60 \mathrm{Nm}^{2}$ As a result of the repetitive application of such large loads, specific adaptions commonly occur to the osseous and soft tissue components of the glenohumeral joint. ${ }^{3-6}$ A combination of these structural adaptations have been shown to modify the normative ROM in the throwing arm, resulting in increased external rotation and decreased internal rotation movements. More specifically, this tightness can result in decreased glenohumeral horizontal adduction $^{7-9}$ and internal rotation motion ${ }^{4,10-13}$ and an increased capacity for injury.,10,1423

Studies have implicated posterior shoulder tightness (PST) as a potential cause of injuries such as muscular dysfunction, ${ }^{24-27}$ superior labral anterior to posterior lesions, ${ }^{20,26,28-33}$ subacromial impingement, ${ }^{7,34}$ and pathological internal impingement. ${ }^{10,24,26,31,35}$ However, pathological implications of PST often only become prevalent once significant losses in ROM have occurred. ${ }^{2,10,14,22,23,36,37}$ A majority of the studies pertaining to ROM changes and PST focus on the loss of the internal rotation, but 
decreased horizontal adduction has also been observed. ${ }^{9,18,38}$ Certain contributing factors to PST, such as posterior capsule and muscular restrictions, ${ }^{3-5,39}$ may be managed effectively with different types of conservative treatment options. ${ }^{40-46}$ Muscle energy techniques (MET) applied to the GH joint have been shown to aid in improving ROM. ${ }^{40}$ Moore et $\mathrm{al}^{40}$ explored the effects of a MET treatment applied to the glenohumeral external rotators compared to the horizontal abductors. These authors determined that treatment to the horizontal abductor muscle group yielded a greater improvement in both internal rotation and horizontal adduction motions when compared to a control group. Joint mobilizations are another form of manual therapy and have been clinically shown to improve joint motion and kinematics. ${ }^{39,47,48}$ Joint mobilizations have also been shown to be an effective technique for decreasing pain and treating pathologies, such as adhesive capsulitis. $^{39,47,48}$

Due to the potential negative effects of PST, determining optimal treatment options for improving glenohumeral internal rotation and horizontal adduction could aid in decreasing the rate and severity of injury in overhead throwing athletes. The purpose of this study was to compare the acute effectiveness of MET and joint mobilizations for reducing PST among high school baseball and softball players. The secondary purpose was to determine if any changes in ROM persisted over a 15 minute time period. We hypothesized that the application of the joint mobilizations would yield the greatest restorative results for PST. 


\section{CHAPTER II}

\section{REVIEW OF LITERATURE}

During overhead sports such as baseball, softball, volleyball, tennis, swimming, and handball the athlete's upper extremity is subject to extreme forces, large torques, and many repetitions in each sporting exposure. The high number of repetitions and the large forces have been shown to relate to the presence of changes in range of motion at the glenohumeral $(\mathrm{GH})$ joint due to both soft tissue and osseous adaptations. The changes in motion can become drastic shifts away from the normal scope of motion, and cause pathologic onset of a variety of conditions. Various treatment methods have been used to decrease the soft tissue adaptations in an attempt to prevent injury. The purpose of this study is to compare the application of muscle energy technique (MET) to the horizontal abductors to posterior joint mobilizations to determine which treatment is most effective for reducing posterior shoulder tightness (PST) acutely and to monitor any lasting effects of either treatment. In order to identify the question, we must first understand the anatomy of the GH joint, the changes that occur in the overhead athlete's shoulder, as

well as the operational definition of PST. The implications of PST as well as an understanding of the types of pathologies affiliated with PST are also essential for this study. Since this study compares treatment methods that can be used to decrease levels of PST, it is important to understand the other types of treatments that have been previously 
examined and proven effective. Overall, the goal of this study is to provide health care professionals with accurate information regarding the most effective method to treat PST, in the hopes of preventing injury and providing optimal therapeutic interventions for the various shoulder pathologies associated with PST.

\section{Anatomy of the Shoulder}

The shoulder consists of three joints: glenohumeral, sternoclavicular, and acromioclavicular. ${ }^{49}$ However, this review of literature will focus on the anatomy of the glenohumeral $(\mathrm{GH})$ joint, where the head of the humerus is received into the glenoid fossa of the scapula, creating a ball-and-socket joint. ${ }^{49}$ The arrangement of the articulation is a contributing factor for the large range of motion present at this joint. The articulating surfaces are protected by a layer of articular cartilage, with the cartilage of the humeral head being thicker in the center as compared to the edges. The opposite is true for the articular cartilage covering the glenoid fossa, as it is thicker around the edge of the cavity, and thinner throughout the middle. ${ }^{49}$

The articulation of the GH joint is supported by the ligamentous structures of the shoulder. Gray ${ }^{49}$ refers to the glenohumeral joint capsule as the capsular ligament and observes that it completely encircles the articulation of the GH joint and attaches to the entire circumference of the glenoid cavity and the anatomical neck of the humerus. The capsular ligament is thicker superior and inferior to the GH joint itself ${ }^{49}$. The capsular ligament has also been described by Gray ${ }^{49}$ as "remarkably loose and lax" which allows for separation of the articulating surfaces, providing the extreme freedom of movement found at the GH joint. 
The GH capsule is strengthened by supplementary bands of ligament located in the interior of the joint ${ }^{49}$. The supplementary bands of the capsule are known as the glenohumeral ligaments, and are clearly separated into three separate segments: the superior, middle and inferior glenohumeral ligaments. ${ }^{50}$ The GH ligaments help resist excessive motion of the GH joint and help prevent dislocation. ${ }^{51}$ Each segment of the glenohumeral ligament resists a specific translation of the humeral head and aids in preventing excessive movement of the humeral head. The superior glenohumeral ligament (SGHL) runs from the supraglenoid tubercle to the lesser tuberosity of the humerus and resists anterior and inferior translations of the humeral head. ${ }^{52,53}$ The SHGL also prevents the dislocation of the biceps tendon from its sulcus. ${ }^{54}$ The middle glenohumeral ligament (MGHL) serves as a key stabilizer of the anterior aspect of the GH joint during the motion of external rotation with concurrent $\mathrm{GH}$ abduction. ${ }^{55}$ The MGHL extends from the superior portion of the glenoid tubercle to the inferior portion of the lesser tuberosity. ${ }^{54}$ The inferior glenohumeral ligament (IGHL) consists of two segments, the anterior band and the posterior band. ${ }^{54}$ The posterior segment of the IGHL prevents excessive posterior translation of the humeral heading during abduction and external rotation movements. ${ }^{52,56}$ However, the primary restraint of anterior translation of the humeral head when the arm is abducted and externally rotated is the anterior band of the inferior GH ligament. ${ }^{57-59}$ The transverse humeral ligament, passing from the lesser to the greater tuberosity of the humerus, and the glenoid labrum, which is a fibrocartilaginous rim around the edge of the glenoid cavity, also provides stability to the GH joint $^{49}$. The glenoid labrum is a fibrocartilaginous structure that deepens the glenoid rim and creates a functional seal around the articulating surface of the humerus. ${ }^{50}$ This 
functional seal generates inter-articular pressure which aids in stabilization of the GH joint and keeping the humeral head centered in the glenoid fossa. ${ }^{50}$

The design of the ball-and-socket joint allows freedom of movement in all directions, especially when combined with proper activation and accessory movement patterns of the scapula and clavicle at the acromioclavicular joint and the sternoclavicular joint. ${ }^{49}$ The humerus is drawn into flexion by the pectoralis major, anterior fibers of the deltoid, coracobrachialis, and by the biceps when the elbow is flexed. ${ }^{49}$ The muscles that contribute to extension are the latissimus dorsi, teres major, posterior fibers of the deltoid, and the triceps when the elbow is extended. ${ }^{49}$ The GH joint is abducted by the middle deltoid and supraspinatus while the subscapularis, pectoralis major, latissimus dorsi and teres major contribute to $\mathrm{GH}$ adduction. ${ }^{49}$ Activation of the infraspinatus and teres minor muscles cause the GH joint to move into external rotation, and contraction of the subscapularis, latissimus dorsi, teres major and pectoralis major cause the GH joint to move into internal rotation. ${ }^{49}$ The $\mathrm{GH}$ joint is moved into horizontal adduction by the anterior deltoid and pectoralis major. ${ }^{60}$ The posterior deltoid, infraspinatus, and teres minor horizontally abduct the GH joint. ${ }^{60}$

Muscle fibers also act as dynamic stabilizers of the GH joint throughout motion. ${ }^{49}$ The primary dynamic stabilizers of the GH joint are the muscles of the rotator cuff as well as the tendon of the long head of the biceps. ${ }^{51}$ The supraspinatus, infraspinatus, teres minor, and subscapularis encase the anterior, superior, and posterior aspects of the GH joint capsule and help resist excessive movement of the humeral head via rhythmic contraction and relaxation. ${ }^{51}$ The tendon of the long head of the biceps acts as a dynamic stabilizer of the anterosuperior aspect of the GH joint due to its origin, and insertion. ${ }^{51}$ 
The nerves that enervate the musculature surrounding the GH joint are derived from the circumflex (axillary), subscapular, musculocutaneous, and suprascapular nerves. ${ }^{49}$

\section{The Overhead Athlete}

Overhead athletes face unique challenges and demands of their sport. The throwing motion often requires high repetitions, extreme velocities, repeated accuracy, and extreme range of motion (ROM) of the GH joint; placing stress on the same body segments with each throw. The external rotation ROM typically seen in the throwing arm of an overhead athlete is approximately 180 degrees, and this extreme motion is required to create the high rotational forces and ball velocity during each throw. ${ }^{1}$ Larger amounts of external rotation allow for a longer throwing arc, which allows for a longer period of time for the athlete to create the rotational torques and angular velocities needed for faster ball speed. ${ }^{10,61}$ The fastest velocities experienced by the human body often occur during the throwing motion. Internal rotation velocity has been observed at peak velocities of 7000 degrees per second, and rotational torques have been recorded near $70 \mathrm{Nm} .{ }^{1,33,62} \mathrm{It}$ has been postulated that these extreme forces and velocities are related to adaptations that occur within the dominant arm of an overhead athlete that are not present within the athlete's non-dominant arm or in non-overhead athletes. ${ }^{2,6,63-65}$ In order to fully understand the relationship between the demands of overhead sports and the adaptations that have been observed within the dominant arm of athletes, it is essential to understand the mechanics and movements of the throwing motion.

Throwing has been described as continuous movement that begins in the lower extremity and core, which provides a strong base of support and helps generate kinetic 
energy that is transferred through the athlete's dominate arm, ending with the release of the ball. ${ }^{66-69}$ The task of throwing requires a sequential transfer of forces and motions through the mechanical linkage of body segments through the kinetic chain, utilizing all portions of the body to complete the motion. ${ }^{70,71}$ The mechanics of the throwing motion have been broken down into six main phases: the wind-up, the stride, arm cocking, acceleration, deceleration, and follow through. ${ }^{24,72}$

The first phase of the throwing motion is the wind-up. During this first phase, the athlete begins in a dual leg stance, transferring their weight to the leg on the throwing side of the body, which is known as the stance leg. ${ }^{67}$ This shift in body weight changes the location of the athlete's center of gravity, positioning it over the stance leg. ${ }^{73}$ The muscles of the stance leg maintain isometric contractions to stabilize the athlete in a single leg stance while maintaining proper positioning for the throwing motion, including a level pelvis, knee flexion, and hip flexion. ${ }^{67}$ The athlete's stride leg, the leg opposite to the throwing side of the body, is elevated and flexed. ${ }^{1,67}$ The trunk and upper body rotate 90 degrees, away from the target of the throw. ${ }^{1,67}$

The second phase of motion is the stride phase, which begins when the athlete separates their hands and ends when the stride foot makes contact with the ground. ${ }^{1,67}$ During this phase the center of gravity continues to lower as the hip of the stance leg moves into flexion. ${ }^{67}$ The stance leg then hip extends, abducts, and internally rotates while the stride leg extends and externally rotates toward the target, initiating forward motion. ${ }^{67}$ The torso begins to rotate toward the target, the dominant arm beings to horizontally abduct and externally rotate, and the scapula protracts, laterally rotates, and tilts anteriorly ${ }^{67}$ Rotation of the torso and lower extremity during this phase is important 
to the velocity of the throw because $51-55 \%$ of the force development occurs in the core and legs, and is transferred up the kinetic chain during the throwing motion. ${ }^{70,74}$

The third phase of motion is the arm cocking phase, which lasts from stride foot contact until max GH external rotation is achieved. ${ }^{1,67,74}$ The muscles of the stride leg contract to decelerate the flexion of the knee, stabilize the leg, and create a stable base for the final phases of the throwing motion. ${ }^{67}$ The pelvis, trunk, and upper torso continue to rotate toward the target with the lumbar spine positioned in hyperextension ${ }^{67}$, with excessive hyperextension limited by an eccentric contraction of the abdominal obliques ${ }^{73}$, and stabilization by the gluteus maximus. ${ }^{75}$ The elbow flexes, and the GH joint externally rotates, and the arm moves into 90 degrees of GH abduction, ${ }^{67}$ approaching maximal external rotation which has been recorded to range from 165 to 180 degrees, ${ }^{1,33,76,77}$ and is capable of producing forces ranging from $550 \mathrm{~N}$ to $770 \mathrm{~N} .^{33,78}$ The scapula reaches maximal retraction and external rotation, and moves into a posterior tilt when the GH joint is in a position of maximum external rotation and maximum abduction. ${ }^{67}$ During this phase, the forearm moves into a position of pronation. ${ }^{70}$ Toward the late cocking phase, the most strain is placed on the anterior glenohumeral capsuloligamentous structures to prevent anterior translation of the humeral head. ${ }^{79}$ Maximal external rotation can be limited by the contact of the greater tuberosity of the humerus and rotator cuff against the posterosuperior glenoid, ${ }^{10}$ but these restrictions have been shown to be overcome by soft tissue adapation. ${ }^{80}$

The fourth phase of the throwing motion is the acceleration phase, which begins when the shoulder reaches a position of maximal external rotation, and ends with ball release. ${ }^{73}$ During this phase the trunk continues to rotate and tilt toward the target 
allowing the energy to transfer to the upper extremity with the shift from hyperextension to controlled forward flexion. ${ }^{67,73}$ The stride leg moves into hip flexion and knee extension. $^{73}$ The GH joint moves into rapid internal rotation, producing maximum force and angular velocity required for the throwing motion, which as been observed as great as $90 \mathrm{Nm}$ of internal rotation torque. ${ }^{73,81}$ Over the course of this phase, the elbow moves from maximum elbow flexion to maximum elbow extension. ${ }^{73}$ The forearm is pronated and the wrist is in a neutral position. ${ }^{73}$

The fifth phase of the throwing motion is the deceleration phase, which begins with ball release and culminates when the $\mathrm{GH}$ joint is in a position of maximum internal rotation. ${ }^{73}$ During this movement phase, the elbow extends, the GH joint moves into continued internal rotation, and begins to move across the body into horizontal adduction. ${ }^{73}$ During deceleration, the musculature of the posterior rotator cuff dissipates the forces that develop during the throwing movement. The greatest amount of tissue loading occurs during the deceleration phase due to increased inferior shear forces, increased compressive forces, and increased adduction torques. ${ }^{67,73}$ The elbow flexors eccentrically contract to slow the motion of elbow extension. ${ }^{67,73}$ The scapula moves from an upwardly rotated position into protraction and an anterior tilt. ${ }^{67,73}$

The final phase of the throwing motion is the follow through. During the follow through, the weight of the athlete is transferred to the stride leg, which extends at the knee. The torso continues to decelerate and also moves into a flexed position over the stride leg. ${ }^{67}$ The GH joint ends in the optimal fielding position of approximately 60 degrees of horizontal adduction. ${ }^{73}$ During both the deceleration and follow through phases, the posterior joint capsule and rotator cuff muscles experience eccentric loads up 
to $108 \%$ of body weight, ${ }^{82}$ with fatigue of the posterior rotator cuff resulting in a greater percentage of the eccentric forces translating through the joint capsule. ${ }^{83,84}$ These unique sport specific demands, high repetitions, and extreme forces experienced during the throwing motion have been postulated to cause adaptive changes within both the osseous and soft tissue components surrounding the GH joint, resulting in ROM changes.

The most commonly reported changes in the range of motion of the dominant arm among overhead athletes include increased external rotation, decreased internal rotation, and decreased horizontal adduction. ${ }^{4,11-13,85}$ The loss of internal rotation has been categorized as glenohumeral internal rotation deficit (GIRD). ${ }^{6,13,18,86-91}$ In order to better analyze the total shift in motion that occurs in the overhead athlete, Wilk et $\mathrm{al}^{5}$ proposed the concept of total rotational motion (TROM), where the measures of IR and ER are combined to obtain an absolute total arc of motion. Surprisingly enough, the measurements of TROM can be equal when compared bilaterally despite the shift in IR and ER. ${ }^{6,12,13,91}$ Equal bilateral measurements of TROM have been recorded in athletes at the professional level ${ }^{2,13,14}$ and in adolescent/developmental athletes. ${ }^{90,92}$ Several different definitions of posterior shoulder tightness (PST) exist within the literature. Pathologic GIRD or PST has been defined by Burkhart et al ${ }^{10,20,93}$ as a loss of 20 degrees or more of IR as compared contralaterally or greater than $10 \%$ loss of TROM seen in the nonthrowing shoulder. Wilk et $\mathrm{al}^{2,14,37}$ has indicated that a bilateral difference in total rotational arc of motion exceeding 5 degrees on the dominant side is representative of PST in the throwing arm. Kibler et $\mathrm{al}^{36}$ suggested that pathological GIRD or PST consisted of a side to side asymmetry of greater that 18 degrees, indicating that large shifts in ROM can be detrimental to the integrity of the GH joint. However, it has been 
reported that as long as the GIRD is less than or equal to the gain in ER, ensuring that TROM remains equal, the throwing shoulder may be at less risk of developing injury. ${ }^{20}$ Changes in GIRD and TROM have been observed to have age related changes, ${ }^{90}$ but the cause of these changes is yet to be determined. Overall, the literature is inconclusive in identifying a singular cause for these changes in ROM.

\section{Osseous Adaptations}

There are two main theories for the changes in ROM that occur at the GH joint; changes to the osseous structures or changes to the soft tissue components of the joint. However, some literature states that both osseous and soft tissue adaptations contribute to the development of GIRD in the throwing shoulder, but the relative contributions of each is still inconclusive. ${ }^{94}$ Studies have shown that accommodating for changes to the humerus only account for approximately 10-17 degrees of rotational motion that is lost due to GIRD. ${ }^{6,95}$ This osseous change is known as humeral retrotorsion, and is defined as the angle created by the humeral head and an axis between the medial and lateral epicondyles of the distal humerus. ${ }^{94}$ An increased angle of retrotorsion results in increased external rotation of the distal humerus as compared to the proximal segment. ${ }^{96}$ Measures of retrotorsion have been shown to clinically effect records of GH measures of $\mathrm{ROM}^{6,91,97}$ since increased levels of retrotorsion allow for excessive external rotation motion while limiting internal rotation, mimicking the appearance of posterior shoulder hypomobility. ${ }^{15}$ It is hypothesized that increased levels of retrotorsion in adult overhead athletes stems from participation in throwing sports before skeletal maturity ${ }^{6,98}$, allowing the rotation torques to influence bone development under the principles of Wolff's Law. ${ }^{99}$ 
At the end of the cocking phase of the throwing motion, the muscular forces and body acceleration create an internal rotation toque at the proximal humerus while the distal humerus and forearm continue to apply an external rotation torque which is responsible for creating the twist along the axis of the humerus. ${ }^{98,99}$ Differences in retrotorsion ranging from 0-29 degrees have been observes in baseball players when compared to non-throwing athletes and when compared to their non-dominant arm. ${ }^{6,91,98,100}$ Hibberd et $\mathrm{al}^{101}$ observed gendered differences when measuring retrotorsion in elite overhead athletes, suggesting that difference in kinetics generated by males and females influences the degree of retrotorsion. Age related increases in GIRD have also been observed with changes in retrotorsion among youth overhead athletes. ${ }^{15}$ Hibberd ${ }^{15}$ monitored levels of retrotorsion as well as total changes in ROM in an attempt to determine the impact of increased retrotorsion on overall ROM. Results demonstrated that there was no significant changes in ROM after measurements were normalized to account for the degree of humeral retrotorsion in each athlete. This allowed the authors to postulate that changes in ROM occurred mainly as a result of increased retrotorsion since there were no overall changes in ROM between subject groups once the data had been normalized to account for increased retrotorsion. ${ }^{15}$ It was also recorded that the largest change in levels of GIRD between age groups also occurred during the time of greatest changes in retrotorsion, ${ }^{15}$ showing a strong relationship between the two measures. ${ }^{15,98}$ Increased levels of retrotorsion in the overhead athlete are significant to the clinician because retrotorsion has been linked to increased performance ${ }^{100}$ and the decreased risk of injury. ${ }^{97,102}$ Evidence shows that increased levels of retrotorsion may help athletes avoid 
injuries due to decreased external rotation ROM needed at the proximal humerus to reach maximal ER, thus potentially decreasing shear forces through the throwing motion. ${ }^{25,103}$

\section{Soft Tissue Adaptations}

After skeletal maturity, any further alterations in range of motion at the GH joint stem from soft tissue adaptation caused by changes to the joint capsule, ligaments, or the musculature of the posterior shoulder. ${ }^{98}$ A majority of the literature focuses on the changes to the joint capsule, and the main theory behind muscular involvement relates to fatigue and contracture caused by excessive eccentric loading during the deceleration phase. ${ }^{83,84}$ The muscles of the posterior shoulder including the posterior rotator cuff and deltoid have been shown to contribute to posterior shoulder tightness (PST) ${ }^{104}$. PST is the combination of contracture of the posterior shoulder musculature and decreased tissue compliance of the joint capsule. PST is prevalent in overhead athletes when GIRD exceeds the amount of internal rotation loss caused by humeral retrotorsion or when IR loss exceeds ER gain. ${ }^{105}$ Use of measurements corrected for osseous contributions to internal rotation loss have been suggested in order to isolate and evaluate the role of PST in the overhead athlete. ${ }^{98}$ It has also been postulated that differences in TROM may be more sensitive to the involvement of PST on ROM measures since TROM should not be

affected by humeral retrotorsion. ${ }^{98}$ A measurement of horizontal adduction ROM has also been proven as a reliable and valid method of recording levels of PST in the overhead athlete. $^{9,38}$

Changes in ROM due to changes in the posterior capsule occur as a result of repetitive stretching and microtrauma caused by the distraction and rotational forces 
during the deceleration and follow through phases of throwing. ${ }^{10,24}$ The repeated microtrauma causes the capsule to shorten and thicken, creating increased ER because the shortened posterior capsule changes the contact point of the humeral head on the surface of the glenoid fossa, shifting it in a posterosuperior direction. ${ }^{10,24}$ The change in the contact point allows the greater tuberosity to clear the glenoid rim, and accounts for the increase in external rotation. ${ }^{10,24}$ Chronic tearing of the posterior capsule due to the immense loading sustained during the deceleration phase of throwing may also result in increased fibroblastic response, increased collagen deposition, and decreased tissue compliance, which in turn leads to increased capsule stiffness. ${ }^{84}$ Studies have also shown that throwers exhibiting GIRD showed a severely thickened and contracted posteroinferior recess in the posterior band of the inferior GH ligament during surgical observations. ${ }^{10}$ Research $^{106}$ has shown that when accounting for humeral retrotorsion in measures of GH rotational motion, ROM can change between two throwing seasons, suggesting that changes in ROM may be transient and responsive to modulation. It has also been shown that internal rotation stretching and posterior capsular release can decrease GIRD, emphasizing the role of soft tissue contracture. ${ }^{89,107,108}$ In the youth athlete, however, it has been suggested that the soft tissue surrounding the shoulder may provide less influence on the integrity of the $\mathrm{GH}$ joint, and therefore, the changes in motion of the youth athlete may possibly be directly related to osseous adaptation. ${ }^{10}$ The changes in osseous alignment and soft tissue extensibility have been shown repeatedly to play a role in changes to ROM in the throwing arm of an overhead athlete. Each factor has also been evaluated as component of GIRD and PST. Excessive alterations in ROM caused by PST have been shown to increase the risk of developing a pathological concern 
in the throwing arm. Understanding the relationship between PST, and injury is essential for the clinician to provide the optimal care for the throwing athlete.

\section{Pathological Implications of PST}

Symptoms of injury in the overhead athlete generally develop with an insidious onset and may not always cause immediate pain or decreased performance. ${ }^{109}$ Generally, the symptoms present as non-specific and broad, most commonly include the inability to "get loose", issues controlling the accuracy of the throw, decreased velocity, increased pain, or the inability to throw. ${ }^{109}$ Several studies have linked PST and alterations in ROM to shoulder pain and injury. ${ }^{7,10,16-19,21,93}$ Several studies have also shown that extreme alterations in ROM, elevated levels of PST, and asymmetrical TROM result in high incidence of injury among overhead athletes. Kevern et $\mathrm{al}^{22}$ has noted that baseball pitchers with greater than 20 degrees of GIRD as compared to the non-dominant side were nearly twice as likely to suffer an injury as those athletes whose measurements of GIRD were less than 20 degrees. An increased incidence of ulnar collateral ligament tears has also been recorded in athletes with significant changes in GH ROM as compared to athletes who did not have excessive loss of IR ROM. ${ }^{23}$ Dines $^{23}$ reported that athletes that suffered a torn UCL in the throwing arm reported an average of $18.8 \%$ of GIRD in the dominant arm as opposed to $8.8 \%$ measure of GIRD in throwing athletes that did not suffer a UCL rupture. The literature has reported that asymmetrical and excessive TROM can also impact the onset of shoulder pathology. Wilk et $\mathrm{al}^{2}$ has shown that pitchers with as little as 5 degrees of GIRD had an increased risk for injury compared to athletes with no presence of GIRD in the dominant arm, showing that even slight alterations in motion 
can become affiliated with pathology. There is a $250 \%$ increased risk of injury among athletes with asymmetrical TROM by 5 degrees or greater. ${ }^{2,14}$ In addition to asymmetrical TROM, excessive TROM is also contributing factor for injury in the throwing athlete. Wilk et a $1^{14}$ reported that $78 \%$ of overhead athletes with a TROM greater than 176 degrees will have an injury. Clinicians have also stated that TROM should not exceed 186 degrees as an absolute measure. ${ }^{36}$ The literature reports that if an athlete does not gain sufficient external rotation to counter-balance lost internal rotation, there is a $230 \%$ increase in risk for injury. ${ }^{37}$ Reports also show that disruption of the kinetic chain at proximal segments, such as the GH joint, can alter movements and forces at the distal segments, resulting in the possible development of injury. ${ }^{70}$ The breakdown in the kinetic chain can arise from variations in motor control, strength deficits, decreased flexibility, and decreased muscular endurance. ${ }^{70,73}$ Common sites of deficiency in the kinetic chain include the legs, core, scapula, and shoulder. ${ }^{70}$

PST has been implicated with several pathologies common to the overhead athlete. ${ }^{63}$ A relationship between PST and labral pathology, most frequently a superior labral anterior to posterior (SLAP) lesions has been noted. It has been reported that injuries to the labrum develop as a results of a variety of mechanisms of injury including: the tensile failure of the long head of the biceps tendon. The long head of the biceps acts as a dynamic stabilizer of the GH joint via eccentric loads placed on the elbow during deceleration. ${ }^{32}$ SLAP lesions can also occur from the torsional forces when the shoulder reaches a position of maximal abduction and maximal external rotation creating the "peel back mechanism", which occurs when forces translated up the long head of the biceps tendon peel the labrum away from the glenoid fossa. ${ }^{110}$ SLAP lesions can also occur 
more acutely when the humeral head translates up and over the labrum as the shoulder is moved into a position of excessive external rotation. ${ }^{33}$ The literature has also suggested that the normal contact between the greater tuberosity and the posterosuperior labrum when the shoulder is abducted and externally rotated can become pathologic as a result of increased frequency. ${ }^{26,31}$ Of the four main types of SLAP tears, Type II lesions, which is defined as an avulsion of the glenoid labrum and biceps anchor from the glenoid rim, ${ }^{29,110}$ have been recorded as the most commonly associated with overhead activity. ${ }^{28-30}$ It has been postulated that labral pathologies have been linked to the mechanisms of the throwing motion due to the torsional forces that occur when the arm is in a position of maximal external rotation and abduction, thought to "peel back" the biceps and labrum. ${ }^{110}$ However, another theory suggests that labral pathologies develop a result of the role of the biceps as a deceleration force acting on the elbow, resulting in tensile failure at the insertion of the biceps. ${ }^{32}$

Posterosuperior impingement, also referred to as internal impingement, is the most common cause of shoulder pain in the throwing athlete, ${ }^{35}$ most commonly experienced during the late cocking and early acceleration phases. ${ }^{26,31}$ Internal impingement is the impingement of the undersurface of the rotator cuff between the greater tuberosity and posterior humerus with the posterosuperior labrum and the glenoid during a position of maximal GH external rotation and abduction. ${ }^{25,111,112}$ The extreme forces generated during these phases can result in the development of impingement and stretching of the anterior joint capsule. ${ }^{10,24}$ Posterior impingement often results in the development of rotator cuff partial substance tears of the supraspinatus and infraspinatus tendons, which can then progress to full substance tears. ${ }^{25,26}$ The posterior rotator cuff 
musculature and posterior capsule may also be susceptible to injury as a result of a shortened throwing motion which does not permit enough time for the proper distribution of forces during the deceleration and follow-through phases. ${ }^{24,27}$ Mihata et al ${ }^{113}$ demonstrated that fatigue of the rotator cuff musculature created increased overlap of the rotator cuff insertion and the glenoid at varying degrees of abduction, linking the formation of internal impingement to changes in the posterior shoulder musculature.

It has been postulated that PST plays a role in the development of subacromial impingement due to abnormal translations of the humeral head. ${ }^{34}$ These abnormal translations have been shown to occur due to the selective tightening the posteroinferior capsule, allowing the humeral head to excessively translate anteriorly, which may decrease the width of the subacromial space. ${ }^{17,34}$

As reported earlier in this review, breakdowns in the proximal segments of the kinetic chain can result in dysfunction at the distal segments, including the elbow. ${ }^{70}$ GIRD has also been implicated in damage to the ulnar collateral ligament in throwers. ${ }^{23}$ PST can play a significant role in the alteration of throwing mechanics, allowing for increased valgus stress on the elbow. If the throwing arm is unable to internally rotate the arm before extending the elbow during the acceleration phase of throwing, a "lag" is created, causing a majority of force production to stem from the elbow, resulting in higher valgus forces. ${ }^{66}$ Excessive external rotation, limited internal rotation, and less than 90 degrees abduction during the acceleration phase also contribute to increased valgus stress at the elbow, resulting in more force transmitted through the UCL. ${ }^{67,70}$ Current findings in the literature support the theory that GIRD and PST are implicated in the development of shoulder and elbow pathology. Due to the incidence of these injuries in 
the overhead athlete, it is beneficial for the clinician to understand the philosophy and results of the various treatments that have been shown to decrease the influence and effects of PST on GH ROM.

\section{Treatments to Reduce PST}

As discussed in previous sections of this literature review, PST is a multifactorial condition with no isolated, singular cause that may result in the development of a variety of shoulder pathologies. As a result of the many factors contributing to the onset of PST, several treatment methods have been examined in an attempt to determine which is most effective for decreasing PST and restoring normative GH ROM.

Several studies have examined the different types of stretching techniques that target the musculature of the posterior shoulder. ${ }^{10,18,41,45,114-117}$ Previous research has suggested a variety of stretching techniques including the towel stretch, ${ }^{118,119}$ the sleeper stretch, ${ }^{10,41,116,120}$ and the cross body stretch ${ }^{45}$ improve GH ROM. The literature surrounding these stretching techniques mainly focuses on the effectiveness of the sleeper stretch and the cross body stretch. The sleeper stretch has the participant in a side-lying position on the side to be stretched with the shoulder and elbow both flexed to 90 degrees. The lateral border of the scapula is stabilized by the treatment table due to the side-lying position, and the distal forearm is moved toward the table, moving the GH joint into a position of internal rotation. ${ }^{41}$ This stretch has been shown to significantly improve PST by increasing both horizontal adduction (HADD) ${ }^{41,121}$ and internal rotation motion. ${ }^{41,121,122}$ Wilk et al ${ }^{5}$ detailed slight modifications to the sleeper stretch protocol, but did not evaluate the effectiveness of those changes, yet they are often used in clinical 
application. Research on stretching techniques has also examined the role of scapular stabilization in both the sleeper stretch and the cross body stretch. ${ }^{45,115}$ A study by McClure et $\mathrm{al}^{45}$ compared the effectiveness of the sleeper stretch to the cross body stretch noting that the patient position during the sleeper stretch stabilizes the scapula firmly against the treatment table, ${ }^{41}$ where as the cross body stretch does not stabilize the scapula and does not isolate the tissues of the glenohumeral joint. ${ }^{45}$ However, this study ${ }^{45}$ reported that the cross body stretch was more effective for increasing IR ROM when compared to a control group. This result was surprising to the authors who expected the stabilized scapula to have a larger contribution to the stretching mechanism. However, this study only examined the effects of stretching on IR ROM as opposed to total PST, which also often includes HADD.$^{45}$ The role of scapular stabilization was further examined by Salamh ${ }^{115}$, who incorporated the stabilization into the cross body stretch. Their results showed that scapular stabilization significantly improved PST via HADD and IR ROM, where as non-stabilization of scapula during the cross body stretch only improved IR ROM. ${ }^{115}$ Yamauchi et al ${ }^{121}$ compared the effectiveness of the modified cross body stretch to the modified sleeper stretch, both with the scapula stabilized, determining that both treatments created significant increases in internal rotation and horizontal adduction ROM, which the modified cross body stretch creating a slightly larger gain in horizontal adduction motion.

The utilization of joint mobilizations has been examined in the treatment of various pathologies that impact GH ROM, primarily adhesive capsulitis. ${ }^{43,47,48,123-125}$ Clinicians have used joint mobilizations as a method for increasing capsular joint mobility and soft tissue extensibility. ${ }^{43,44,46,126}$ The effectiveness of joint mobilizations 
has yet to be determined due non-consistent results amongst studies, ${ }^{43,47,123-125}$ as well as inconsistencies in the method of treatment application varying in intensity and duration. However, there have been successes in treating GH joint ROM disorders, primarily adhesive capsulitis, with joint mobilizations in the inferior, posterior and anterior directions, ${ }^{47}$ as well as anterior to posterior and posterior to anterior glides. ${ }^{48}$ Vermeulen et $\mathrm{al}^{47}$ examined high grade and low grade mobilizations in patients with adhesive capsulitis and determined that the more aggressive high end (Maitland grade III mobilizations) had greater results in increasing abduction and external rotation ROM, both actively and passively as wells as decreasing disability measures, pain scores, and general health and activity limitations. The low end mobilizations (Maitland grade II mobilizations) also had significant improvements over the baseline measures but not as large as the high end mobilizations. ${ }^{47}$ Gutierrez et al ${ }^{127}$ compared posterior joint mobilizations to traditional physical therapy exercise for the rehabilitation of adhesive capsulitis, recording the effects of each treatment protocol on passive range of motion and overall levels of pain. The results of this study determined that both treatment protocols yielded a significant improvement in all outcome measures as compared to a control group, the individuals treated with joint mobilizations improved dramatically in ROM measures and in decreased levels of pain over the group treated with an exercise regiment. ${ }^{127}$ Despite the fact that joint mobilizations have been shown as an effective treatment for ROM pathologies of the $\mathrm{GH}$ joint, there is no literature that examines the singular effects of joint mobilizations on treating the changes to ROM that occur at the GH joint as a result of PST and GIRD. The literature that examines the use of mobilizations on PST also implemented a stretching protocol concurrently with the 
mobilization treatment. ${ }^{128-130}$ All three studies ${ }^{128-130}$ that were found for the purposes of this literature review found significant changes in IR ROM after a combination treatment of stretching protocol and joint mobilizations. Significant results for stretching only protocol in all three studies also produced significant results when compared to baseline measures. ${ }^{128-130}$ Harshbarger ${ }^{131}$ discussed that none of the results found on the comparison of stretching and joint mobilizations ${ }^{128-130}$ yielded significant changes at follow up times and there is still a need for the development of a treatment that creates lasting changes.

Muscle energy technique (MET) is another commonly used treatment for improving soft tissue mobility. Muscle energy technique is a type of manual therapy that consists of an active contraction of the target muscle group met with a precise, clinician controlled counter force that is followed by a passive stretch of the target muscle group. ${ }^{132}$ The use of MET has been validated through research for strengthening and lengthening muscles, reducing edema, improving circulation, and mobilizing restricted articulations. ${ }^{132}$ Schenk et al ${ }^{133}$ evaluated the effectiveness of MET to improve cervical flexion, extension, axial rotation and lateral flexion in subjects with predetermined ROM limitations. The MET treatment protocol was applied over a 4 week treatment period, with multiple sessions per week, yielding significant results for improvements in cervical extension ROM. ${ }^{133}$ Schenk also investigate the effects of MET on the lumbar spine, ${ }^{134}$ applying a protocol similar to that of cervical spine MET study. ${ }^{133}$ The results demonstrated that MET effectively restored lumbar extension ROM after a 4 week treatment protocol, validating the use of MET as a treatment for lumbar spine hypomobility. ${ }^{134}$ Lenehan ${ }^{135}$ and Ballantyne ${ }^{136}$ further examined the effectiveness of 
MET, limiting the treatment application to a single treatment session to evaluate the acute effects of MET on ROM restoration. Lenehan ${ }^{135}$ explored the effects of MET on gross trunk ROM, finding that a single application of MET significantly improved ROM in subject with rotatory restrictions and a non-significant improvement of ROM in subjects that did not present with any ROM restrictions. The results of this study indicate that MET is an effective treatment for both symptomatic and asymptomatic individuals. Ballantyne ${ }^{136}$ produced similar results when treating hamstring extensibility with a single application of MET. A single application of MET has been proven effective in increasing passive knee extension in asymptomatic subjects. ${ }^{136}$ MET has been proven an effective treatment for mobilizing the cervical spine and lumbar spine, improving gross trunk movement, and improving hamstring extensibility ${ }^{133-136}$ however, there is no significant literature regarding the application of MET to the shoulder complex. Laudner et al ${ }^{137}$ explored the effectiveness to the anterior portion of the shoulder girdle, evaluating the effectiveness of MET to lengthen the pectoralis minor in order to improve forward shoulder posture. MET proved to be an effective treatment, creating significant results for improving the length of the pectoralis minor over the course of a 6 week treatment program. ${ }^{137}$ Moore ${ }^{40}$ has been the only study that applied MET treatments for the management of PST via treatment of the horizontal abductor muscle group. Results found significant improvements in horizontal abduction when compared to a control group and significantly greater improvements in internal rotation when compared to a control group and a group who received MET applied to the GH external rotators. ${ }^{40}$

After reviewing the literature surrounding the treatment options that have evaluated for effectiveness of managing PST, it is clear that there is a void in the 
literature that examines the isolated effects of joint mobilizations and muscle energy techniques on PST. There is also no literature that compares treatments that target the capsular components of PST to the treatments targeting the muscular contributions to PST. These gaps in the literature have prompted the investigators of this study to design a protocol to test these considerations in an attempt to determine the effectiveness of joint mobilizations for reducing the capsular component of PST while comparing to a MET treatment.

\section{Conclusion}

The review of this literature provided insight on the anatomy of the shoulder, the sport specific demands of overhead athletes, an oversight into PST, various pathologies related to the development of PST, and a review of treatments used in reducing PST. The knowledge of these topics will help clinicians understand the purpose of this study; whether an application of MET applied to the horizontal adductors or an application of posterior glenohumeral joint mobilizations is more effective in reducing PST through increased glenohumeral internal rotation ROM. 


\section{CHAPTER III}

\section{METHODS}

\section{Materials and Methods}

This study utilized a randomized controlled trial design. The independent variables included group (muscle energy technique (MET), joint mobilizations, and control). The dependent variables were glenohumeral horizontal adduction and internal rotation ROM immediately following treatment and 15-minutes post-treatment.

\section{Participants}

The participants who volunteered for this study consisted of youth throwing athletes recruited from two different high schools. Inclusion criteria required participants to be a current member of a competitive high school baseball or softball team. Participants were excluded from the study if they had any recent history (past 3 months) of upper extremity injury that prevented participation in their respective sport. The total number of participants for this study was 42 (24 male, 18 female). Thirty-six participants were right-hand dominant throwing athletes, while six were left hand dominant throwing athletes. Participant demographics can be viewed in Table 1. 


\begin{tabular}{|l|l|l|l|}
\hline \multicolumn{4}{|c|}{ Table 1. Participant Demographics } \\
\hline Group & Age (years) & Height (cm) & Mass (kg) \\
& & & $69.81 \pm 12.9$ \\
\hline MET (n=14) & $17.07 \pm 1.0$ & $176.17 \pm 14.7$ & $71.88 \pm 17.4$ \\
\hline Joint Mobs $(\mathrm{n}=14)$ & $16.43 \pm 0.8$ & $172.72 \pm 11.4$ & $72.23 \pm 26.6$ \\
\hline Controls $(\mathrm{n}=14)$ & $16.50 \pm 1.2$ & $174.46 \pm 11.4$ &
\end{tabular}

MET = muscle energy technique; joint mobs $=$ joint mobilization

\section{Instrumentation}

A Pro 3600 digital inclinometer (SPI-Tronic, Garden Grove, CA, USA) was used to record ROM measurements for glenohumeral horizontal adduction, external rotation, and internal rotation.

\section{Procedures}

Participant Consent, Demographics, and Group Allocation

Each participant and their parents or legal guardians completed the necessary consent and assent forms as required by the Institutional Review Board prior to reporting for testing. Participant demographic information was recorded and included age, height $(\mathrm{cm})$, body mass $(\mathrm{kg})$, injury history, and throwing arm preference. Group allocation (control, MET, joint mobilizations) was determined prior to participation in this study, such that an equal number of participants were randomly assigned to each group based on subject number.

All participants completed three testing sessions (pre-test, immediate post-test, 15 minutes following post-test). The immediate post-test measurements were recorded directly following the treatment application for the experimental groups and after a one 
minute waiting period for the control group. All participants then waited an additional 15minutes for a second round of post-tests.

\section{$\underline{\text { Data Collection }}$}

Data collection occurred during the midpoint of the competitive season for all participants. Prior to data collection, participants completed their team's specific standard warm-up. The warm up consisted of mild jogging cardiovascular activity, static and dynamic total body stretches, and low velocity overhead/throwing motions with few repetitions. The warm up for this study was not standardized in order to mimic the normal playing conditions and regular training regimen for each specific participant. After completing the warm up, each participant was assessed for a baseline measurement of horizontal adduction and the total arc of internal/external rotation in their dominant and non-dominant arms.

\section{$\underline{\text { Range of Motion Assessments }}$}

To assess GH horizontal adduction ROM, each participant was positioned supine with both shoulders flush against a standard examination table. A tester stood at the top of the examination table towards the participant's head and stabilized the lateral border of the scapula by providing a posterior force. The participant was placed in a position of 90 degrees of GH abduction with 90 degrees of elbow flexion. The opposite hand of the clinician held just distal to the participant's elbow and passively horizontally adducted the arm (Figure 1). At the end of the motion a second tester recorded the amount of motion present by aligning the digital inclinometer with the shaft of the humerus. 
GH internal and external rotation were measured with the participant lying supine on the examination table, with the shoulder abducted to 90 degrees and the elbow in 90 degrees of flexion. The clinician applied a posterior stabilizing force to the acromion processes of the scapula, and internally rotated the arm until

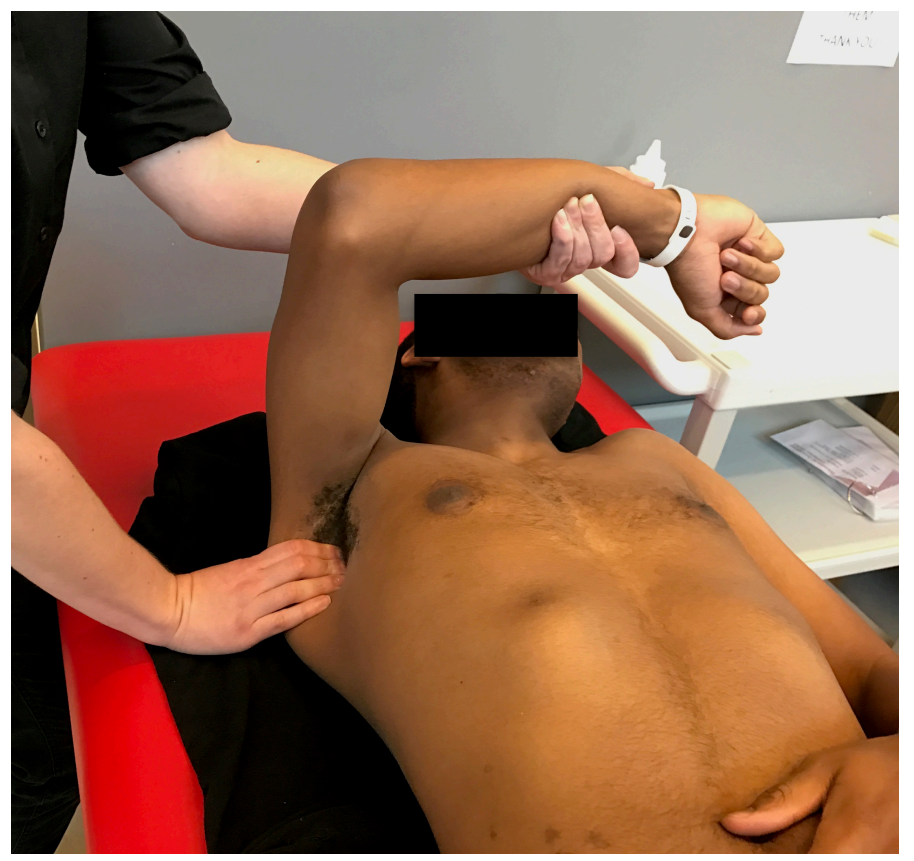

Figure 1. Horizontal ROM Measurement the first point of resistance. A second clinician recorded the amount of motion by aligning the digital inclinometer with the shaft of the ulna. GH external rotation motion was collected using the same technique. All post-test measurements were performed in an identical manner to the pretest measurements. The order of the ROM measurements was not randomized.

A pilot test consisting of 16 subjects was completed a priori to determine intrarater reliability and the standard error of measurements (SEM) for all ROM tests. Each subject had their bilateral ROM measured resulting in 32 limbs tested. Subjects were tested and then repeated the tests a minimum of 24 hours later. All measurements showed excellent intra-rater reliability and SEM (horizontal adduction: $r=.85, \mathrm{SEM}=2.3$ degrees, external rotation: $r=.97, \mathrm{SEM}=3.4$ degrees, internal rotation: $r=.87, \mathrm{SEM}=4.2$ degrees). 


\section{Interventions}

The participants that received the joint mobilization intervention were positioned supine along the edge of the examination table, so that the glenohumeral joint did not have any support in a posterior direction. The participant's arm was abducted to 90 degrees and internally rotated to the first barrier of resistance, with the elbow flexed and relaxed (Figure 2). The

participant's distal forearm was braced on the clinician's hip as a support, with the clinician's hand applying overpressure to the $\mathrm{GH}$ joint in the posterior direction. The clinician then mobilized the humeral head in a posterior direction. Fifteen grade III posterior mobilizations were applied to the humeral head at

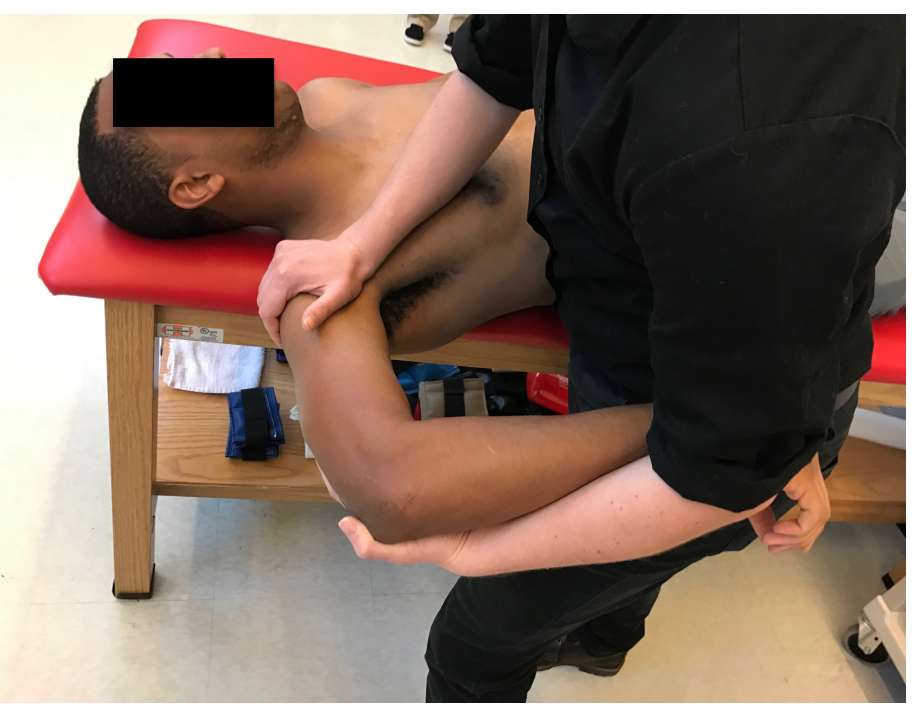

Figure 2. Joint Mobilizations the glenoid, with one second of rest between mobilizations over a 30 second period.

The participants in the muscle energy technique (MET) treatment group were positioned supine on the examination table with the clinician stabilizing the lateral border of the scapula. The clinician passively horizontally adducted the arm until the first barrier to motion, applying a passive stretch for three seconds. The clinician then instructed the 
participant to attempt to horizontally abduct the test arm at $25 \%$ of their maximal effort while the clinician applied manual resistance to create an isometric contraction lasting five seconds. The clinician then brought the participant's arm back into horizontal adduction, for a three second active assistive stretch. Four of these application cycles were completed in total.

\section{Statistical Methods}

SPSS Statistical software SPSS (IBM SPSS Statistics for Windows, version 22.0; IBM Corp, Armonk, NY) was used to analyze the data. Statistical analyses were conducted via separate one-way analyses of covariance (ANCOVA) for horizontal adduction and internal rotation. The dependent variables consisted of post-test ROM and the covariates were pre-test ROM. Fisher's least significant difference post hoc analysis was used when appropriate. All analyses were considered significant at the 0.05 alpha level. Effect sizes were calculated using the formula (experimental group mean - control group mean) / largest standard deviation. 


\section{CHAPTER IV}

\section{RESULTS}

Results

The descriptive pre-test ROM values for all groups are provided in Table 2 . The results of this study showed there was a significant between group difference for postintervention horizontal adduction $\operatorname{ROM}(\mathrm{F}(2,38)=8.7 ; p=0.001)$. Post hoc analysis showed that the shoulders treated with MET had significantly more horizontal adduction ROM post-treatment compared with the control group $(p=0.04)$ (Table 3$)$. There were no significant differences between joint mobilizations and MET $(p=0.16)$ or joint mobilizations and control $(p=0.48)$ for horizontal adduction (Table 3). As for IR ROM there was no significant between group difference post-intervention $(\mathrm{F}(2,38)=1.3 ; p=$ .28) (Table 4). When analyzing the results of measurements collected 15 minutes post intervention, there was no significance between groups differences for either horizontal adduction $(\mathrm{F}(2,38)=0.4 ; p=0.70)$ or $\operatorname{IR}(\mathrm{F}(2,38)=0.1 ; p=0.91)($ Tables $3 \& 4)$.

Table 2. Pre-intervention Range of Motion Measures $\left(^{\circ}\right)$

\begin{tabular}{|c|c|c|c|}
\hline Group & Internal Rotation & External Rotation & Total Arc \\
\hline MET & $53.2 \pm 8.9$ & $116.5 \pm 8.9$ & $169.7 \pm 12.1$ \\
\hline Joint Mobs & $55.4 \pm 11.5$ & $115.7 \pm 10.6$ & $171.1 \pm 19.0$ \\
\hline Control & $55.2 \pm 9.8$ & $114.5 \pm 15.5$ & $169.7 \pm 20.2$ \\
\hline
\end{tabular}

MET=muscle energy technique; Joint Mobs=joint mobilization 
Table 3. Means and Standard Deviations for Horizontal Adduction Range of Motion

\begin{tabular}{|c|c|c|c|c|c|c|c|}
\hline Group & $\begin{array}{c}\text { Pre Test } \\
\left({ }^{\circ}\right)\end{array}$ & $\begin{array}{c}\text { Acute Post } \\
\text { Test }\left({ }^{\circ}\right)\end{array}$ & $\begin{array}{c}\text { Difference } \\
\left({ }^{\circ}\right)\end{array}$ & $\begin{array}{c}\text { Effect } \\
\text { Size }\end{array}$ & $\begin{array}{c}\text { 15 Minutes } \\
\text { Post Test }\left(^{\circ}\right)\end{array}$ & $\begin{array}{c}\text { Difference } \\
\left({ }^{\circ}\right)\end{array}$ & $\begin{array}{c}\text { Effect } \\
\text { Size }\end{array}$ \\
\hline MET* & $15.6 \pm 7.7$ & $24.0 \pm 7.4$ & $8.3 \pm 7.6$ & .73 & $17.8 \pm 5.7$ & $2.2 \pm 5.7$ & .02 \\
\hline Joint Mobs & $18.5 \pm 5.8$ & $19.9 \pm 6.9$ & $1.4 \pm 4.0$ & .24 & $19.1 \pm 7.4$ & $0.6 \pm 5.4$ & .13 \\
\hline Control & $18.6 \pm 9.7$ & $17.9 \pm 8.4$ & $-0.7 \pm 5.0$ & .07 & $18.0 \pm 8.2$ & $-0.6 \pm 7.1$ & .06 \\
\hline
\end{tabular}

MET $=$ muscle energy technique; Joint Mobs=joint mobilization

$*=$ Significant difference between MET and control groups $(p=0.04)$

Table 4. Means and Standard Deviations for Internal Rotation Range of Motion

\begin{tabular}{|c|c|c|c|c|c|c|c|}
\hline Group & $\begin{array}{c}\text { Pre Test } \\
\left({ }^{\circ}\right)\end{array}$ & $\begin{array}{c}\text { Acute Post } \\
\text { Test }\left(^{\circ}\right)\end{array}$ & $\begin{array}{c}\text { Difference } \\
\left({ }^{\circ}\right)\end{array}$ & $\begin{array}{c}\text { Effect } \\
\text { Size }\end{array}$ & $\begin{array}{c}\text { 15 Minutes } \\
\text { Post Test }\left({ }^{\circ}\right)\end{array}$ & $\begin{array}{c}\text { Difference } \\
\left({ }^{\circ}\right)\end{array}$ & $\begin{array}{c}\text { Effect } \\
\text { Size }\end{array}$ \\
\hline MET & $53.2 \pm 8.9$ & $58.2 \pm 9.4$ & $5.0 \pm 5.5$ & .04 & $54.6 \pm 10.0$ & $1.4 \pm 6.8$ & .28 \\
\hline Joint Mobs & $55.4 \pm 11.5$ & $57.9 \pm 11.8$ & $2.5 \pm 4.1$ & .02 & $57.3 \pm 10.6$ & $1.9 \pm 4.6$ & .06 \\
\hline Control & $55.2 \pm 9.8$ & $57.7 \pm 10.5$ & $2.5 \pm 3.6$ & .24 & $58.0 \pm 12.1$ & $2.9 \pm 6.2$ & .23 \\
\hline
\end{tabular}

$\mathrm{MET}=$ muscle energy technique; Joint Mobs=joint mobilization

\section{Discussion}

Athletes that participate in throwing sports place specific demands on the upper extremity, such as the extreme velocities and high repetitions, often present with PST. ${ }^{2,6,63-65}$ This tightness has been repeatedly shown to alter shoulder ROM, ${ }^{4,6,11-13,18,85-91}$ kinematics, ${ }^{70,73,109}$ and kinetics. ${ }^{70,73,101}$ Alterations to glenohumeral ROM in the overhead athlete have been linked to various pathologies including muscular dysfunction, ${ }^{24-27}$ labral lesions, ${ }^{20,26,28-33}$ and impingement syndromes, ${ }^{7,10,24,26,31,34,35}$ as well as decreased performance. ${ }^{109}$ In order to prevent and treat various pathologies related to this tightness, it is essential to implement techniques that lengthen both the contractile and noncontractile tissues of the posterior shoulder. The results of this study demonstrate that the application of MET to the horizontal abductors provides acute improvements in $\mathrm{GH}$ horizontal adduction ROM in high school baseball and softball players. 
Despite the importance of maintaining normal ROM in the overhead athlete to prevent the development of altered kinetics during the throwing motion, there is no definitive consensus on which manual therapy provides the most significant reductions in PST. Previous literature has determined that a variety of stretching techniques targeting the musculature of the posterior shoulder are effective methods for reducing the ROM discrepancies associated with PST. ${ }^{10,18,41,45,114-117}$ Studies have demonstrated that the towel stretch, ${ }^{118,119}$ the sleeper stretch ${ }^{10,41,116,120}$ and the cross body stretch ${ }^{45}$ are all beneficial. The bulk of the literature on the effectiveness of stretching techniques pertains to the sleeper stretch and the cross body stretch. Both stretches have been proven effective for increasing horizontal adduction and internal rotation, with the largest increases in both motions occurring when the scapula is stabilized during both stretching techniques. ${ }^{45,115,121}$ Research focused on the use of stretching techniques has validated that treatments targeting the soft tissue components of the GH joint are an effective method to decrease PST. Because our application of MET targeted several muscles of the glenohumeral joint our results would support these previous findings.

In addition to the use of stretching techniques to improve range of motion, MET has also been explored as a treatment targeting the soft tissue extensibility issues behind motion restrictions. A series of studies have validated the use of MET for increasing range of motion by observing the effects on different segments and directions of trunk motion ${ }^{133-135}$ and hamstring extensibility. ${ }^{136}$ Relatively few studies have applied this technique to the upper extremity, ${ }^{40,137}$ however these past studies have shown strong evidence validating MET for improving ROM. 
Moore et al., ${ }^{40}$ examined the effects of a MET application to the shoulder external rotators and horizontal abductors with a similar technique as used in this study. This previous study demonstrated that the horizontal abductors responded well to an acute MET treatment, creating significant improvements in horizontal adduction and IR ROM. The results of our study support those of Moore ${ }^{40}$ as we were also able to produce increased horizontal adduction. However, Moore also reported a significant improvement in internal rotation. This could be due to several factors, such as Moore's use of a larger sample size and a longer stretch phase during the MET intervention.

Moore et al., ${ }^{40}$ discussed that at the time of their publication it was unknown if muscular or capsular tightness was a larger contributor to PST and the associated ROM changes. Although, this debate still has not be resolved, our results seem to indicate that the lack of response from the joint mobilizations may be due to the decreased role of the posterior capsule. Conversely, previous research has postulated that capsular tightness contributes significantly to PST. ${ }^{10,24}$ Several studies have shown that joint mobilizations are an effective method for treating conditions such as adhesive capsulitis, by targeting the motion restrictions created through capsular tightening and increasing motion. ${ }^{43,47,48,123-125,127}$ However, the literature surrounding the use of joint mobilizations to decrease PST has not yet examined the isolated effects of joint mobilizations, but rather paired the mobilizations with a series of different stretching and therapeutic exercise protocols. ${ }^{128-130}$ Our findings support previous studies that focused on muscular extensibility. ${ }^{5,10,18,40-42,114-117,137}$ Our findings may suggest that the contributions of the GH capsule in the development of PST is limited, especially in high school baseball and softball players. As such, youth athletes may have not experienced the same degree of 
posterior capsular tightening as an adult overhead athlete. However, further research is needed to explore this topic.

The effects of the MET treatment were transient, lasting less than 15 minutes. Research ${ }^{106}$ has shown that ROM can change between two throwing seasons, suggesting that changes in ROM may be reversible and responsive to modulation. The transient nature of these changes emphasizes the clinical importance of preventative treatments that may reduce the prevalence of shoulder pathologies over time. The results of our study indicate the effectiveness of MET for short term changes in improving GH ROM and decreasing PST. Similarly, previous research has shown that repeated treatments applied to the soft tissue components of the GH joint are effective in creating improvements to GH ROM. ${ }^{45,137}$ Unfortunately, there is little research determining the duration of the lasting changes to the length of the GH musculature. Furthermore, athletes who perform MET prior to sport participation may see longer lasting results when immediately followed by their sport activity, as opposed to being static, as during our study. However, future research is needed to validate this hypothesis.

The MET application to the horizontal abductor group yielded significant improvements in horizontal adduction when compared to the control group. This result revealed a moderate-to-large effect size as evaluated by Cohen's $d(0.73)$. The difference between the pre- and post-test values ( 8.3 degrees) was also larger than the SEM (2.3 degrees), which may indicate clinical significance. The results of our study demonstrate that MET applied to the horizontal abductors are beneficial in treating this tightness. As such, this type of intervention should be considered in the prevention and treatment of a 
variety of shoulder injuries associated with PST, such as superior labrum anterior-

posterior lesions, ${ }^{20,28-30,110}$ internal impingement, ${ }^{18,35}$ and subacromial impingement. ${ }^{7,17,34}$

\section{Limitations}

The population of this study consisted of youth athletes, limiting the application of these results to older athletic populations. The subjects were also limited to participation in baseball and softball, limiting the generalizability of these results to other overhead sports such as volleyball and tennis that also often present with PST. This study evaluated the effects of these treatments in asymptomatic subjects. Those with a pathologic conditions may respond to MET in a different manner. The results of this study indicate that a single application of MET is an effective method of acutely decreasing PST. Future research should be directed toward observing any potential lasting changes in glenohumeral ROM and PST following a course of multiple MET applications.

Conclusion

Our findings indicate that a single application of MET to the glenohumeral horizontal abductors significantly increases horizontal adduction ROM among high school baseball and softball players. However, the effects of the treatment were transient, lasting less than 15 minutes. The application of MET did not have any significant effect on internal rotation motion. Our findings also indicate that the results created by the application of joint mobilizations were negligible at both the immediate posttest and the delayed posttest for both horizontal adduction and internal rotation measures. Therefore, 
the application of MET to the horizontal abductors may assist in treating PST in youth baseball and softball players.

\section{Conflict of Interest}

The authors of this study do not have any conflicts of interest to report that would have interfered with or altered the results of this study. 


\section{REFERENCES}

1. Dillman CJ, Fleisig GS, Andrews JR. Biomechanics of pitching with emphasis upon shoulder kinematics. J Orthop Sports Phys Ther. 1993;18(2):402-408.

2. Wilk KE, Macrina LC, Fleisig GS, et al. Correlation of glenohumeral internal rotation deficit and total rotational motion to shoulder injuries in professional baseball pitchers. Am J Sports Med. 2011;39(2):329-335.

3. Borsa PA, Wilk KE, Jacobson JA, et al. Correlation of range of motion and glenohumeral translation in professional baseball pitchers. Am J Sports Med. 2005;33(9):1392-1399.

4. Reinold MM, Wilk KE, Macrina LC, et al. Changes in shoulder and elbow passive range of motion after pitching in professional baseball players. Am J Sports Med. 2008;36(3):523-527.

5. Wilk KE, Meister K, Andrews JR. Current concepts in the rehabilitation of the overhead throwing athlete. Am J Sports Med. 2002;30(1):136-151.

6. Crockett HC, Gross LB, Wilk KE, et al. Osseous adaptation and range of motion at the glenohumeral joint in professional baseball pitchers. Am J Sports Med. 2002;30(1):20-26.

7. Tyler TF, Nicholas SJ, Roy T, Gleim GW. Quantification of posterior capsule tightness and motion loss in patients with shoulder impingement. Am J Sports Med. 2000;28(5):668-673.

8. Myers JB, Oyama S, Wassinger CA, et al. Reliability, precision, accuracy, and validity of posterior shoulder tightness assessment in overhead athletes. Am J Sports Med. 2007;35(11):1922-1930.

9. Tyler TF, Roy T, Nicholas SJ, Gleim GW. Reliability and validity of a new method of measuring posterior shoulder tightness. J Orthop Sports Phys Ther. 1999;29(5):262-269; discussion 270-264.

10. Burkhart SS, Morgan CD, Kibler WB. The disabled throwing shoulder: spectrum of pathology Part I: pathoanatomy and biomechanics. Arthroscopy. 2003;19(4):404-420.

11. Bigliani LU, Codd TP, Connor PM, Levine WN, Littlefield MA, Hershon SJ. Shoulder motion and laxity in the professional baseball player. Am J Sports Med. 1997;25(5):609-613.

12. Brown LP, Niehues SL, Harrah A, Yavorsky P, Hirshman HP. Upper extremity range of motion and isokinetic strength of the internal and external shoulder rotators in major league baseball players. Am J Sports Med. 1988;16(6):577-585.

13. Ellenbecker TS, Roetert EP, Bailie DS, Davies GJ, Brown SW. Glenohumeral joint total rotation range of motion in elite tennis players and baseball pitchers. Med Sci Sports Exerc. 2002;34(12):2052-2056. 
14. Wilk KE, Macrina LC, Arrigo C. Passive range of motion characteristics in the overhead baseball pitcher and their implications for rehabilitation. Clin Orthop Relat Res. 2012;470(6):1586-1594.

15. Hibberd EE, Oyama S, Myers JB. Increase in humeral retrotorsion accounts for age-related increase in glenohumeral internal rotation deficit in youth and adolescent baseball players. Am J Sports Med. 2014;42(4):851-858.

16. Grossman MG, Tibone JE, McGarry MH, Schneider DJ, Veneziani S, Lee TQ. A cadaveric model of the throwing shoulder: a possible etiology of superior labrum anterior-to-posterior lesions. J Bone Joint Surg Am. 2005;87(4):824-831.

17. Harryman DT, Sidles JA, Clark JM, McQuade KJ, Gibb TD, Matsen FA. Translation of the humeral head on the glenoid with passive glenohumeral motion. J Bone Joint Surg Am. 1990;72(9):1334-1343.

18. Myers JB, Laudner KG, Pasquale MR, Bradley JP, Lephart SM. Glenohumeral range of motion deficits and posterior shoulder tightness in throwers with pathologic internal impingement. Am J Sports Med. 2006;34(3):385-391.

19. Ruotolo C, Price E, Panchal A. Loss of total arc of motion in collegiate baseball players. J Shoulder Elbow Surg. 2006;15(1):67-71.

20. Burkhart SS, Morgan CD, Kibler WB. The disabled throwing shoulder: spectrum of pathology. Part II: evaluation and treatment of SLAP lesions in throwers. Arthroscopy. 2003;19(5):531-539.

21. Warner JJ, Micheli LJ, Arslanian LE, Kennedy J, Kennedy R. Patterns of flexibility, laxity, and strength in normal shoulders and shoulders with instability and impingement. Am J Sports Med. 1990;18(4):366-375.

22. Kevern MA, Beecher M, Rao S. Reliability of measurement of glenohumeral internal rotation, external rotation, and total arc of motion in 3 test positions. $J$ Athl Train. 2014;49(5):640-646.

23. Dines JS, Frank JB, Akerman M, Yocum LA. Glenohumeral internal rotation deficits in baseball players with ulnar collateral ligament insufficiency. Am J Sports Med. 2009;37(3):566-570.

24. Fleisig GS, Barrentine SW, Escamilla RF, Andrews JR. Biomechanics of overhand throwing with implications for injuries. Sports Med. 1996;21(6):421437.

25. Walch G, Boileau P, Noel E, Donell ST. Impingement of the deep surface of the supraspinatus tendon on the posterosuperior glenoid rim: An arthroscopic study. $J$ Shoulder Elbow Surg. 1992;1(5):238-245.

26. Walch G, Liotard JP, Boileau P, Noël E. [Postero-superior glenoid impingement. Another impingement of the shoulder]. J Radiol. 1993;74(1):47-50.

27. Gowan ID, Jobe FW, Tibone JE, Perry J, Moynes DR. A comparative electromyographic analysis of the shoulder during pitching. Professional versus amateur pitchers. Am J Sports Med. 1987;15(6):586-590.

28. Handelberg F, Willems S, Shahabpour M, Huskin JP, Kuta J. SLAP lesions: a retrospective multicenter study. Arthroscopy. 1998;14(8):856-862.

29. Snyder SJ, Karzel RP, Del Pizzo W, Ferkel RD, Friedman MJ. SLAP lesions of the shoulder. Arthroscopy. 1990;6(4):274-279.

30. Snyder SJ, Banas MP, Karzel RP. An analysis of 140 injuries to the superior glenoid labrum. J Shoulder Elbow Surg. 1995;4(4):243-248. 
31. Bennett GE. Shoulder and Elbow Lesions Distinctive of Baseball Players. Ann Surg. 1947;126(1):107-110.

32. Andrews J, Gillogy S. Physical examination of the shoulder in throwing athletes. Injuries to the throwing arm. Philadelphia, PA: WB Saunders; 1985.

33. Fleisig GS, Andrews JR, Dillman CJ, Escamilla RF. Kinetics of baseball pitching with implications about injury mechanisms. Am J Sports Med. 1995;23(2):233239.

34. Huffman GR, Tibone JE, McGarry MH, Phipps BM, Lee YS, Lee TQ. Path of glenohumeral articulation throughout the rotational range of motion in a thrower's shoulder model. Am J Sports Med. 2006;34(10):1662-1669.

35. Rossi F. Shoulder impingement syndromes. Eur J Radiol. 1998;27 Suppl 1:S4248.

36. Kibler WB, Kuhn JE, Wilk K, et al. The disabled throwing shoulder: spectrum of pathology-10-year update. Arthroscopy. 2013;29(1):141-161 e126.

37. Wilk K, Macrina L, Fleisig G, al. e. Correlation of shoulder range of motion and shoulder injuries in professional baseball pitchers: A 8 year prospective study. AOSSM Annual Conference; 2013.

38. Laudner KG, Stanek JM, Meister K. Assessing posterior shoulder contracture: the reliability and validity of measuring glenohumeral joint horizontal adduction. $J$ Athl Train. 2006;41(4):375-380.

39. Yu IY, Jung IG, Kang MH, Lee DK, Oh JS. Immediate effects of an end-range mobilization technique on shoulder range of motion and skin temperature in individuals with posterior shoulder tightness. J Phys Ther Sci. 2015;27(6):17231725.

40. Moore SD, Laudner KG, McLoda TA, Shaffer MA. The immediate effects of muscle energy technique on posterior shoulder tightness: a randomized controlled trial. J Orthop Sports Phys Ther. 2011;41(6):400-407.

41. Laudner KG, Sipes RC, Wilson JT. The acute effects of sleeper stretches on shoulder range of motion. J Athl Train. 2008;43(4):359-363.

42. Laudner K, Compton BD, McLoda TA, Walters CM. Acute effects of instrument assisted soft tissue mobilization for improving posterior shoulder range of motion in collegiate baseball players. Int J Sports Phys Ther. 2014;9(1):1-7.

43. Nicholson GG. The effects of passive joint mobilization on pain and hypomobility associated with adhesive capsulitis of the shoulder. J Orthop Sports Phys Ther. 1985;6(4):238-246.

44. Conroy DE, Hayes KW. The effect of joint mobilization as a component of comprehensive treatment for primary shoulder impingement syndrome. J Orthop Sports Phys Ther. 1998;28(1):3-14.

45. McClure P, Balaicuis J, Heiland D, Broersma ME, Thorndike CK, Wood A. A randomized controlled comparison of stretching procedures for posterior shoulder tightness. J Orthop Sports Phys Ther. 2007;37(3):108-114.

46. McClure P, Flower K. Treatment of limited shoulder motion: a case study based on biomechanical considerations. Physical Therapy. 1992(72):929-936.

47. Vermeulen HM, Rozing PM, Obermann WR, le Cessie S, Vliet Vlieland TP. Comparison of high-grade and low-grade mobilization techniques in the 
management of adhesive capsulitis of the shoulder: randomized controlled trial. Phys Ther. 2006;86(3):355-368.

48. Lin HT, Hsu AT, An KN, Chang Chien JR, Kuan TS, Chang GL. Reliability of stiffness measured in glenohumeral joint and its application to assess the effect of end-range mobilization in subjects with adhesive capsulitis. Man Ther. 2008;13(4):307-316.

49. Gray H. Gray's Anatomy. Fifteenth ed. New York, NY: Barnes \& Noble, Inc; 2010.

50. Drake R, Vogl A, Mitchell A. Gray's anatomy for students. 2nd ed. Philedelphia, PA: Churchill Livingstone/Elsevier; 2010.

51. Hsu H, Boardman Nr, ZP L, An K. Tendon-defect and muscle-unloaded models for relating a rotator cuff tear to glenohumeral stability. Journal of Orthopedic Research. 2000;18(6):952-958.

52. Wilk KE, Arrigo CA, Andrews JR. Current concepts: the stabilizing structures of the glenohumeral joint. J Orthop Sports Phys Ther. 1997;25(6):364-379.

53. Warner JJ, Deng XH, Warren RF, Torzilli PA. Static capsuloligamentous restraints to superior-inferior translation of the glenohumeral joint. Am J Sports Med. 1992;20(6):675-685.

54. Tischer T, Vogt S, Kreuz PC, Imhoff AB. Arthroscopic anatomy, variants, and pathologic findings in shoulder instability. Arthroscopy. 2011;27(10):1434-1443.

55. Burkart AC, Debski RE. Anatomy and function of the glenohumeral ligaments in anterior shoulder instability. Clin Orthop Relat Res. 2002(400):32-39.

56. O'Brien S, Schwartz R, Warren R, Torzilli P. Capsular restraints to an anterior/posterior motion at the shoulder. Orthop Trans. 1988;12(143).

57. O'Brien S, Schwartz R, Warren R, Torzilli P. Capsular restraints to anteriorposterior motion of the abducted shoulder: A biomechanical study. Journal of Elbow Surgery. 1995;4(4):298-308.

58. O'Connell PW, Nuber GW, Mileski RA, Lautenschlager E. The contribution of the glenohumeral ligaments to anterior stability of the shoulder joint. Am J Sports Med. 1990;18(6):579-584.

59. McMahon PJ, Tibone JE, Cawley PW, et al. The anterior band of the inferior glenohumeral ligament: biomechanical properties from tensile testing in the position of apprehension. J Shoulder Elbow Surg. 1998;7(5):467-471.

60. Starkey C, Brown SD, Ryan J. Examination of orthopedic and athletic injuries. 3rd ed. Philadelphia, PA: F. A. Davis Company; 2010.

61. Chang IY, Polster JM. Pathomechanics and Magnetic Resonance Imaging of the Thrower's Shoulder. Radiol Clin North Am. 2016;54(5):801-815.

62. Fleisig GS, Barrentine SW, Zheng N, Escamilla RF, Andrews JR. Kinematic and kinetic comparison of baseball pitching among various levels of development. $J$ Biomech. 1999;32(12):1371-1375.

63. Manske R, Wilk KE, Davies G, Ellenbecker T, Reinold M. Glenohumeral motion deficits: friend or foe? Int J Sports Phys Ther. 2013;8(5):537-553.

64. Borsa PA, Dover GC, Wilk KE, Reinold MM. Glenohumeral range of motion and stiffness in professional baseball pitchers. Med Sci Sports Exerc. 2006;38(1):2126. 
65. Osbahr DC, Cannon DL, Speer KP. Retroversion of the humerus in the throwing shoulder of college baseball pitchers. Am J Sports Med. 2002;30(3):347-353.

66. Chu SK, Jayabalan P, Kibler WB, Press J. The Kinetic Chain Revisited: New Concepts on Throwing Mechanics and Injury. PM R. 2016;8(3 Suppl):S69-77.

67. Weber AE, Kontaxis A, O'Brien SJ, Bedi A. The biomechanics of throwing: simplified and cogent. Sports Med Arthrosc. 2014;22(2):72-79.

68. Davids K, Glazier P, Araújo D, Bartlett R. Movement systems as dynamical systems: the functional role of variability and its implications for sports medicine. Sports Med. 2003;33(4):245-260.

69. Kibler WB. Biomechanical analysis of the shoulder during tennis activities. Clin Sports Med. 1995;14(1):79-85.

70. Kibler WB, Wilkes T, Sciascia A. Mechanics and pathomechanics in the overhead athlete. Clin Sports Med. 2013;32(4):637-651.

71. Sciascia A, Thigpen C, Namdari S, Baldwin K. Kinetic chain abnormalities in the athletic shoulder. Sports Med Arthrosc. 2012;20(1):16-21.

72. Werner SL, Gill TJ, Murray TA, Cook TD, Hawkins RJ. Relationships between throwing mechanics and shoulder distraction in professional baseball pitchers. Am J Sports Med. 2001;29(3):354-358.

73. Seroyer ST, Nho SJ, Bach BR, Bush-Joseph CA, Nicholson GP, Romeo AA. Shoulder pain in the overhead throwing athlete. Sports Health. 2009;1(2):108120.

74. Lintner D, Noonan TJ, Kibler WB. Injury patterns and biomechanics of the athlete's shoulder. Clin Sports Med. 2008;27(4):527-551.

75. Calabrese GJ. Pitching mechanics, revisited. Int J Sports Phys Ther. 2013;8(5):652-660.

76. Pappas AM, Zawacki RM, Sullivan TJ. Biomechanics of baseball pitching. A preliminary report. Am J Sports Med. 1985;13(4):216-222.

77. Werner SL, Fleisig GS, Dillman CJ, Andrews JR. Biomechanics of the elbow during baseball pitching. J Orthop Sports Phys Ther. 1993;17(6):274-278.

78. M F, J D. Dynamics of the shoulder and elbow joints of the throwing arm during a baseball pitch. International Journal of Sport Biomechanics. 1986;2:235-259.

79. Kuhn JE, Bey MJ, Huston LJ, Blasier RB, Soslowsky LJ. Ligamentous restraints to external rotation of the humerus in the late-cocking phase of throwing. A cadaveric biomechanical investigation. Am J Sports Med. 2000;28(2):200-205.

80. Jobe FW, Moynes DR, Tibone JE, Perry J. An EMG analysis of the shoulder in pitching. A second report. Am J Sports Med. 1984;12(3):218-220.

81. Wilk KE, Macrina LC, Fleisig GS, et al. Deficits in Glenohumeral Passive Range of Motion Increase Risk of Shoulder Injury in Professional Baseball Pitchers: A Prospective Study. Am J Sports Med. 2015.

82. Borsa PA, Laudner KG, Sauers EL. Mobility and stability adaptations in the shoulder of the overhead athlete: a theoretical and evidence-based perspective. Sports Med. 2008;38(1):17-36.

83. Thomas SJ, Swanik CB, Higginson JS, et al. A bilateral comparison of posterior capsule thickness and its correlation with glenohumeral range of motion and scapular upward rotation in collegiate baseball players. J Shoulder Elbow Surg. 2011;20(5):708-716. 
84. Thomas SJ, Swanik CB, Higginson JS, et al. Neuromuscular and stiffness adaptations in division I collegiate baseball players. J Electromyogr Kinesiol. 2013;23(1):102-109.

85. Ellenbecker TS, Roetert EP, Piorkowski PA, Schulz DA. Glenohumeral joint internal and external rotation range of motion in elite junior tennis players. $J$ Orthop Sports Phys Ther. 1996;24(6):336-341.

86. McFarland EG, Wasik M. Epidemiology of collegiate baseball injuries. Clin $J$ Sport Med. 1998;8(1):10-13.

87. Downar JM, Sauers EL. Clinical Measures of Shoulder Mobility in the Professional Baseball Player. J Athl Train. 2005;40(1):23-29.

88. Johnson L. Patterns of shoulder flexibility among college baseball players. $J$ Athl Train. 1992;27(1):44-49.

89. Lintner D, Mayol M, Uzodinma O, Jones R, Labossiere D. Glenohumeral internal rotation deficits in professional pitchers enrolled in an internal rotation stretching program. Am J Sports Med. 2007;35(4):617-621.

90. Meister K, Day T, Horodyski M, Kaminski TW, Wasik MP, Tillman S. Rotational motion changes in the glenohumeral joint of the adolescent/Little League baseball player. Am J Sports Med. 2005;33(5):693-698.

91. Reagan KM, Meister K, Horodyski MB, Werner DW, Carruthers C, Wilk K. Humeral retroversion and its relationship to glenohumeral rotation in the shoulder of college baseball players. Am J Sports Med. 2002;30(3):354-360.

92. Shanley E, Rauh MJ, Michener LA, Ellenbecker TS, Garrison JC, Thigpen CA. Shoulder range of motion measures as risk factors for shoulder and elbow injuries in high school softball and baseball players. Am J Sports Med. 2011;39(9):19972006.

93. Burkhart SS, Morgan CD, Kibler WB. The disabled throwing shoulder: spectrum of pathology Part III: The SICK scapula, scapular dyskinesis, the kinetic chain, and rehabilitation. Arthroscopy. 2003;19(6):641-661.

94. Greenberg EM, Fernandez-Fernandez A, Lawrence JT, McClure P. The Development of Humeral Retrotorsion and Its Relationship to Throwing Sports. Sports Health. 2015;7(6):489-496.

95. Meister K. Injuries to the shoulder in the throwing athlete. Part one: Biomechanics/pathophysiology/classification of injury. Am J Sports Med. 2000;28(2):265-275.

96. Yoshida M, Saho Y, Katayose M. Reliability of measuring humeral retroversion using ultrasound imaging in a healthy nonthrowing population. J Sport Rehabil. 2010;19(2):149-160.

97. Pieper HG. Humeral torsion in the throwing arm of handball players. Am J Sports Med. 1998;26(2):247-253.

98. Myers JB, Oyama S, Goerger BM, Rucinski TJ, Blackburn JT, Creighton RA. Influence of humeral torsion on interpretation of posterior shoulder tightness measures in overhead athletes. Clin J Sport Med. 2009;19(5):366-371.

99. Sabick MB, Kim YK, Torry MR, Keirns MA, Hawkins RJ. Biomechanics of the shoulder in youth baseball pitchers: implications for the development of proximal humeral epiphysiolysis and humeral retrotorsion. Am J Sports Med. 2005;33(11):1716-1722. 
100. Whiteley RJ, Ginn KA, Nicholson LL, Adams RD. Sports participation and humeral torsion. J Orthop Sports Phys Ther. 2009;39(4):256-263.

101. Hibberd EE, Oyama S, Tatman J, Myers JB. Dominant-limb range-of-motion and humeral-retrotorsion adaptation in collegiate baseball and softball position players. J Athl Train. 2014;49(4):507-513.

102. Myers JB, Oyama S, Rucinski TJ, Creighton RA. Humeral retrotorsion in collegiate baseball pitchers with throwing-related upper extremity injury history. Sports Health. 2011;3(4):383-389.

103. Polster JM, Bullen J, Obuchowski NA, Bryan JA, Soloff L, Schickendantz MS. Relationship between humeral torsion and injury in professional baseball pitchers. Am J Sports Med. 2013;41(9):2015-2021.

104. Michener LA, McClure PW, Karduna AR. Anatomical and biomechanical mechanisms of subacromial impingement syndrome. Clin Biomech (Bristol, Avon). 2003;18(5):369-379.

105. Kinsella SD, Thomas SJ, Huffman GR, Kelly JD. The thrower's shoulder. Orthop Clin North Am. 2014;45(3):387-401.

106. Shanley E, Thigpen CA, Clark JC, et al. Changes in passive range of motion and development of glenohumeral internal rotation deficit (GIRD) in the professional pitching shoulder between spring training in two consecutive years. J Shoulder Elbow Surg. 2012;21(11):1605-1612.

107. Braun S, Kokmeyer D, Millett PJ. Shoulder injuries in the throwing athlete. $J$ Bone Joint Surg Am. 2009;91(4):966-978.

108. Yoneda M, Nakagawa S, Mizuno N, et al. Arthroscopic capsular release for painful throwing shoulder with posterior capsular tightness. Arthroscopy. 2006;22(7):801.e801-805.

109. Manske R, Ellenbecker T. Current concepts in shoulder examination of the overhead athlete. Int J Sports Phys Ther. 2013;8(5):554-578.

110. Burkhart SS, Morgan CD. The peel-back mechanism: its role in producing and extending posterior type II SLAP lesions and its effect on SLAP repair rehabilitation. Arthroscopy. 1998;14(6):637-640.

111. Jobe CM. Superior glenoid impingement. Current concepts. Clin Orthop Relat Res. 1996(330):98-107.

112. Jobe CM. Superior glenoid impingement. Orthop Clin North Am. 1997;28(2):137143.

113. Mihata T, Gates J, McGarry MH, Lee J, Kinoshita M, Lee TQ. Effect of rotator cuff muscle imbalance on forceful internal impingement and peel-back of the superior labrum: a cadaveric study. Am J Sports Med. 2009;37(11):2222-2227.

114. Wilk KE, Hooks TR, Macrina LC. The modified sleeper stretch and modified cross-body stretch to increase shoulder internal rotation range of motion in the overhead throwing athlete. J Orthop Sports Phys Ther. 2013;43(12):891-894.

115. Salamh PA, Kolber MJ, Hanney WJ. Effect of scapular stabilization during horizontal adduction stretching on passive internal rotation and posterior shoulder tightness in young women volleyball athletes: a randomized controlled trial. Arch Phys Med Rehabil. 2015;96(2):349-356.

116. Bach HG, Goldberg BA. Posterior capsular contracture of the shoulder. $\mathrm{J} \mathrm{Am}$ Acad Orthop Surg. 2006;14(5):265-277. 
117. Kibler WB, Chandler TJ. Range of motion in junior tennis players participating in an injury risk modification program. J Sci Med Sport. 2003;6(1):51-62.

118. McClure PW, Bialker J, Neff N, Williams G, Karduna A. Shoulder function and 3-dimensional kinematics in people with shoulder impingement syndrome before and after a 6-week exercise program. Phys Ther. 2004;84(9):832-848.

119. Bandy W, Sanders B. Therapeutic Exercise: Techniques for Intervention. Baltimore, MD: Lippincott Williams \& Wilkins; 2001.

120. Weldon EJ, Richardson AB. Upper extremity overuse injuries in swimming. A discussion of swimmer's shoulder. Clin Sports Med. 2001;20(3):423-438.

121. Yamauchi T, Hasegawa S, Nakamura M, et al. Effects of two stretching methods on shoulder range of motion and muscle stiffness in baseball players with posterior shoulder tightness: a randomized controlled trial. J Shoulder Elbow Surg. 2016;25(9):1395-1403.

122. Reuther KE, Larsen R, Kuhn PD, Kelly JD, Thomas SJ. Sleeper stretch accelerates recovery of glenohumeral internal rotation after pitching. J Shoulder Elbow Surg. 2016;25(12):1925-1929.

123. Bulgen DY, Binder AI, Hazleman BL, Dutton J, Roberts S. Frozen shoulder: prospective clinical study with an evaluation of three treatment regimens. Ann Rheum Dis. 1984;43(3):353-360.

124. Vermeulen H, Obermann W, Burger B, et.al. End-range mobilization techniques in adhesive capsulitis of the shoulder joint: a multiple-subject case report. Physical Therapy. 2000;80:1204-1213.

125. Maricar N, Chok B. A comparison of the effect of manual therapy with exercise therapy and exercise therapy alone for stiff shoulders. Physiotherapy Singapore. 1999;2:99-104.

126. Ekelund AL, Rydell N. Combination treatment for adhesive capsulitis of the shoulder. Clin Orthop Relat Res. 1992(282):105-109.

127. Gutiérrez Espinoza H, Pavez F, Guajardo C, Acosta M. Movilización posterior glenohumeral versus tratamiento kinésico convencional en la capsulitis adhesi. Medwave. 2015;15(8).

128. Cools A, Johansson F, Cagnie B, Cambier D, Witvrouw E. Stretching the posterior shoulder structures in subjects with internal rotation deficit: comparison of two stretching techniques. Vol 4. Shoulder Elbow2012:56-63.

129. Manske RC, Meschke M, Porter A, Smith B, Reiman M. A randomized controlled single-blinded comparison of stretching versus stretching and joint mobilization for posterior shoulder tightness measured by internal rotation motion loss. Sports Health. 2010;2(2):94-100.

130. Tyler TF, Nicholas SJ, Lee SJ, Mullaney M, McHugh MP. Correction of posterior shoulder tightness is associated with symptom resolution in patients with internal impingement. Am J Sports Med. 2010;38(1):114-119.

131. Harshbarger ND, Eppelheimer BL, Valovich McLeod TC, Welch McCarty C. The effectiveness of shoulder stretching and joint mobilizations on posterior shoulder tightness. J Sport Rehabil. 2013;22(4):313-319.

132. Goodridge JP. Muscle energy technique: definition, explanation, methods of procedure. J Am Osteopath Assoc. 1981;81(4):249-254.

133. Schenk R, Adelman K, Rousselle J. The Effects of Muscle Energy Technique on 
Cervical Range of Motion Journal of Manual and Manipulative Therapy. 1994;2(4):149-155.

134. Schenk R, MacDiarmid A, Rousselle J. The Effects of Muscle Energy Technique on Lumbar Range of Motion. Journal of Manual and Manipulative Therapy. 1997;5(4):179-183.

135. Lenehan K, Fryer G, McLaughlin P. The effect of muscle energy technique on gross trunk range of motion. J Osteopath Med. 2003;6:13-18.

136. Ballantyne F, Fryer G, McLaughlin P. The effect of muscle energy technique on hamstring extensibility: the mechanism of altered flexibility. J Osteopath Med. 2003;6:59-63.

137. Laudner KG, Wenig M, Selkow NM, Williams J, Post E. Forward Shoulder Posture in Collegiate Swimmers: A Comparative Analysis of Muscle-Energy Techniques. J Athl Train. 2015;50(11):1133-1139. 